\title{
Prevalence of HBV and HCV infections, Bhutan, 2017: Progress and next steps
}

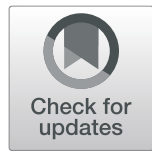

\author{
N. Tshering ${ }^{1}$, G. P. Dhakal ${ }^{2}$, U. Wangchuk ${ }^{3}$, S. Wangdi ${ }^{3}$, L. Khandu' ${ }^{1}$ S. Pelden ${ }^{4}$, F. Nogareda ${ }^{5}$, M. K. Patel ${ }^{5}$, \\ Y. J. F. Hutin ${ }^{5,6^{*}}$ D, K. Wannemuehler ${ }^{7}$ B. B. Rewari ${ }^{8}$ and S. Wangchuk ${ }^{4}$
}

\begin{abstract}
Background: Bhutan is committed to eliminating hepatitis B and hepatitis $C$, though recent baseline estimates of disease burden in the general population are unknown. In 2017, we carried out a biomarker survey in the general population to estimate the prevalence of hepatitis B virus (HBV) and hepatitis $C$ virus ( $\mathrm{HCV}$ ) biomarkers to evaluate the impact of immunization and guide further efforts.

Methods: In 2017, a cross-sectional, population-based, three-stage cluster survey was undertaken of the general population (1-17 and 20+ years of age). We visited households, collected blood specimens and administered a standard questionnaire. Specimens were collected for hepatitis B surface antigen ( $\mathrm{HBsAg}$ ) and hepatitis C virus antibody (anti-HCV) testing. We calculated prevalence of infection and selected characteristics, along with confidence intervals (Cls).

Results: Of 1372 individuals approached, 1358 (99\%) participated. Of those, 1321 (97\%) had a specimen tested for HBsAg, and among 1173 enrolled individuals 5 years of age or older, 1150 (98\%) individuals were tested for anti-HCV. The prevalence of HBsAg was $2.0 \%$ in 775 persons 20 years of age or older (95\% Cl: 1.0-4.0) and $0.5 \%$ in 546 persons $1-17$ years of age ( $95 \% \mathrm{Cl}: 0.1-1.8)$. The prevalence of anti-HCV was $0.3 \%$ ( $95 \% \mathrm{Cl}: 0.1-0.8$ ) among persons $\geq 5$ years.

Conclusions: Universal hepatitis B immunization of infants has resulted in a low prevalence of chronic HBV infection in persons 1-17 years of age and the prevalence of anti-HCV is low among persons aged $\geq 5$ years. Efforts should continue to reach high coverage of the timely birth dose along with completion of the hepatitis $B$ vaccine series. To reduce the chronic liver disease burden among adults, HBV and HCV testing and treatment as indicated might be restricted to pregnant women, blood donors, individuals with chronic liver diseases, and other groups with history of high-risk exposures.
\end{abstract}

Keywords: Hepatitis B, Epidemiology, Immunization, Prevention of mother to child transmission, Perinatal infections, Evaluation, Survey HBsAg

\footnotetext{
*Correspondence: hutiny@who.int

The findings and conclusions in this report are those of the authors and do not necessarily represent the official position of the Centers for Disease Control and Prevention.

${ }^{5}$ WHO Headquarters, 20 Avenue Appia, 1211 Geneva, Switzerland

${ }^{6}$ WHO Regional Office for the Eastern Mediterranean Region, Monazamet El

Seha El Alamia Street, Nasr City, Po Box 7608, Cairo 11371, Egypt

Full list of author information is available at the end of the article
}

(C) The Author(s). 2020 Open Access This article is licensed under a Creative Commons Attribution 4.0 International License, which permits use, sharing, adaptation, distribution and reproduction in any medium or format, as long as you give appropriate credit to the original author(s) and the source, provide a link to the Creative Commons licence, and indicate if changes were made. The images or other third party material in this article are included in the article's Creative Commons licence, unless indicated otherwise in a credit line to the material. If material is not included in the article's Creative Commons licence and your intended use is not permitted by statutory regulation or exceeds the permitted use, you will need to obtain permission directly from the copyright holder. To view a copy of this licence, visit http://creativecommons.org/licenses/by/4.0/ The Creative Commons Public Domain Dedication waiver (http://creativecommons.org/publicdomain/zero/1.0/) applies to the data made available in this article, unless otherwise stated in a credit line to the data. 


\section{Background}

WHO estimates that in 2015, viral hepatitis led to 1.34 million deaths worldwide [1]. Sequelae of chronic infections with hepatitis $B$ virus (HBV) and hepatitis $C$ virus (HCV) accounted for more than $90 \%$ of viral hepatitis mortality [1]. In 2016, the World Health Assembly (WHA) approved the first Global Health Sector Strategy (GHSS) on viral hepatitis [2]. The GHSS on viral hepatitis calls for elimination of viral hepatitis as a public health threat by 2030 , defined as reducing incidence by $90 \%$ and mortality by $65 \%$. By 2020 , the GHSS also proposes to reach $\leq 1 \%$ prevalence of chronic HBV infection among children 5 years of age. In 2016, the South East Asia Region's Immunization Technical Advisory Group established a regional goal to achieve $\leq 1 \%$ prevalence of hepatitis B surface antigen (HBsAg) among 5-year-old children by 2020 (http://www.searo.who.int/immunization/ documents/sear_itag_2016.pdf?ua=1). To formulate action plans for elimination, burden of disease estimates are needed. Since most chronic HBV and HCV infections are asymptomatic [3], biomarker surveys in the general population are necessary [4]. In the WHO South East Asia Region, countries have started to conduct initial assessments to inform and prioritize national strategies.

The Kingdom of Bhutan had an estimated population of 807,000 in 2017 (United Nations population estimates). In 1995-96, a serological survey indicated that $5.9 \%$ of the general population were HBsAg positive $[5,6]$ (intermediate endemicity for chronic HBV infection, i.e., 2-8\% prevalence of HBsAg [7]). In 1997, a three-dose hepatitis B vaccine schedule was introduced into the Expanded Programme on Immunization [EPI]. From 2000 and 2004 onwards, coverage stabilized above 80 and $90 \%$, respectively. In 2012, a hepatitis B vaccine birth dose was added to the childhood immunization schedule. Birth dose coverage was $29 \%$ in 2011, increased to about $60 \%$ in 2012-2013, and further increased to $82 \%$ in 2016 , based on administrative reports.

In 2016, anecdotal reports from clinicians identified a large number of adult patients with chronic liver disease in health care facilities (Guru Prasad Dhakal, Jigme Dorji Wangchuk National Referral Hospital, Thimphu, Bhutan, personal communication); a high proportion of these patients were too old to have received hepatitis $B$ vaccination and had chronic $\mathrm{HBV}$ infection. However, the prevalence of hepatitis viral infections among adults in the general population was unknown, since no biomarker surveys have been conducted since 1997. Moreover, a population-based biomarker survey among children was needed to document progress towards reaching the regional hepatitis $\mathrm{B}$ control goal. Therefore, a cross-sectional biomarker sero-survey was conducted to estimate the prevalence of $\mathrm{HBV}$ and $\mathrm{HCV}$ infections among those born before 1997 and after 2000, in order to (1) evaluate the impact of hepatitis $B$ vaccination on the burden of chronic HBV infection in children and (2) quantify the burden of chronic hepatitis $B$ and $C$ virus infections in adults. The findings were used to inform development of a national viral hepatitis plan.

\section{Methods \\ Design}

The design was a cross-sectional, population-based, three-stage cluster survey. We integrated the survey with a measles-rubella serological survey to reduce cost and improve efficiencies. This report describes the hepatitis $B$ and $C$ results.

\section{Population}

The survey population consisted of household members living in Bhutan at the time of the survey. Three age groups were defined: 1) persons born from 1 April 2012 to 31 March 2016 who were aged 1-4 years ('young children') at the time of the survey; 2) persons born from 1 April 2000 to 31 March 2012 who were aged 5-17 years ('older children') at the time of the survey. 1 April 2000 was chosen to include children who had had an opportunity to receive three doses of hepatitis B vaccine after the vaccine was introduced in 1997, excluding period from 1997 to 1999 when coverage was low); and 3) persons born before 1997 who were aged $\geq 20$ years ('adults') at the time of the survey.

\section{Operational definitions}

We defined chronic $\mathrm{HBV}$ infection as the presence of $\mathrm{HBsAg}$, past or present $\mathrm{HCV}$ infection as the presence of $\mathrm{HCV}$ antibodies, and chronic $\mathrm{HCV}$ infection as the presence of HCV RNA.

\section{Sampling \\ Sample size}

To address the primary objective of the survey (estimating the prevalence of HBsAg among adults and older children), the sample size was estimated on the basis of the expected prevalence of the biomarker in the surveyed population, the absolute precision, and the intraclass cluster correlation. For younger and older children together, we expected a prevalence of $1 \%$ (the regional control goal threshold), an absolute precision of $1 \%$ and a design effect of 1.5. This generated a sample size of 571 children, using the asymptotic formula, increased to 657 children after adjustment for an anticipated 15\% non-response. For adults, we expected a HBsAg prevalence of $5 \%$ (the prevalence before hepatitis $\mathrm{B}$ vaccine introduction), an absolute precision of $2 \%$ and a design effect of 1.5. This generated a sample size of 685 adults, increased to 788 after adjustment for an anticipated 15\% non-response. For younger children aged 1-4 years, we also calculated a minimum effective sample size based 
on the sample size needed for the concomitant measlesrubella serosurvey. Sample size was calculated based on the assumption of an expected 95\% seroprevalence of measles immunoglobulin (IgG), a desired precision of a one-sided confidence interval of $-5 \%$ and a significance level $\alpha=0.05$, which resulted in an effective sample size of 123 (Fleiss formula). Accounting for the cluster design with a target of eight young children per primary sampling unit, an intraclass correlation $=0.1$, and an anticipated $15 \%$ nonresponse, the sample size was increased to 245 young children. A design of 30 clusters with 29 households per cluster was chosen to achieve the minimum sample size in each age group.

\section{Cluster sampling}

The sample was stratified to separate Thimphu, the capital, from the rest of the country, in order not to oversample in the most populous area of the country. In the first stage, four gewogs (i.e., blocks of villages, with population size around 4000) were chosen from Thimphu and 26 from the rest of country, by probability proportional to estimated size with replacement from a national census list. In the second stage, an updated household line list was created from which 29 households were randomly selected and visited. At each household, field workers listed those eligible individuals (anyone who had been living in the household for the last 6 months, regardless of presence at home during the first visit). One participant was selected from each of the three age groups. If there was more than one eligible individual in an age group, one was selected at random using a random number generated by a cell phone application (third sampling stage). In case of absences, field workers revisited up to three times on two different days. If the selected individual remained absent after 2 days, the individual was counted as absent and not replaced.

\section{Data collection}

Trained field workers administered one of three standardized questionnaires (based on the age group) to the enrolled individuals or their parents after obtaining written consent (and assent as appropriate). The questionnaire included demographic characteristics (e.g., age, gender, residence); hepatitis $\mathrm{B}$ vaccination history; each participant's or caregiver's knowledge of HBV or HCV infection status; and exposures that could be risk factors for HBV or HCV infection. Vaccination data were verified by reviewing vaccination cards in those 1-17 years of age when available. Questions were asked in a private setting to ensure confidentiality. Pre-test counselling was conducted as per the WHO guidelines on viral hepatitis testing. Written consent was requested for individuals in all three age groups for hepatitis B testing and among older children and adults for hepatitis $\mathrm{C}$ testing. Venous blood was collected from consenting selected individuals following standard quality control. Plasma was separated at the nearest Basic Health Unit (BHU), stored at $-20^{\circ} \mathrm{C}$, and sent to Royal Centre for Disease Control (RCDC) under temperature control for testing.

\section{Laboratory testing}

At RCDC, quality assurance and quality control in specimen processing were carried out using standard operating procedures of the laboratory. The survey specimens were tested together with quality control specimens supplied by the National Reference Laboratory, Melbourne, Australia [8]. HBsAg testing was performed using the MUREX HBsAg Version 3 (DiaSorin UK, United Kingdom); and for HCV, anti-HCV antibody testing was conducted using the INNOTEST HCV Ab IV (Fujirebio Europe, Belgium). Participants who were HBsAg positive who could be followed up were tested for quantitative HBV DNA, and those who were anti-HCV positive were tested for $\mathrm{HCV}$ RNA at an ISO 9001-2000 certified, College of American Pathologists accredited clinical laboratory in New Delhi, India on a second specimen.

\section{Return of tests results to participants}

After laboratory testing was completed, investigators returned the results of the hepatitis $B$ and $C$ tests to the participants, if positive, and provided post-test counselling according to WHO guidelines on viral hepatitis testing [6]. Investigators organized referral for further assessment, care and treatment for those testing $\mathrm{HBsAg}$ or anti-HCV positive.

\section{Analysis plan}

Data were double entered using Epi $\mathrm{Info}^{\mathrm{m}} \mathrm{v} 7$. Weights were applied, taking into account the sampling strategy, non-response, and the population distribution in Bhutan. Concerning vaccination, timely hepatitis $B$ birth dose (HepB-BD) was defined as a dose given on the day of birth or on the day after birth. Frequencies, weighted percentages, and $95 \%$ logit confidence intervals were calculated for all items. We compared populations with and without selected characteristics in terms of prevalence of biomarkers through the calculation of prevalence ratios and their 95\% CIs.

\section{Human subjects protection}

The Research \& Ethical Board of Health, Bhutan, and the WHO Research Ethics Review Committee approved the survey protocol after the necessary amendments (Bhutan: REBH/Approval/2017/008; WHO: ERC.0002874). This activity was reviewed in accordance with CDC human research protections procedures and was determined to be nonresearch, programme evaluation. 


\section{Results}

\section{Recruitment of participants}

In March-April 2017, 870 households were visited in 30 clusters in 13 districts (Dzongkhags). Among them, 781 (90\%) households agreed to participate in the survey with at least one member of the household, 18 (2\%) households refused to participate, and 71 (8\%) were ineligible (non-residential, abandoned, or no adults available). From the 781 participating households, 1372 individuals were approached for participation. Of those, 1358 (99\%) individuals were interviewed (779 adults aged $\geq 20$ years, 394 children aged 5-17 years and 185 children aged 1-4 years); 1321 (97\%) blood specimens were collected and tested for HBsAg; and specimens from 1150 (98\%) of 1173 older children and adults were tested for anti-HCV.

\section{Chronic HBV infection prevalence}

Of the 775 adults tested (median age: 41 years, interquartile range: $32-53), 15$ (2\%, 95\% CI 1-4\%) were HBsAg positive (Table 1). Of the 375 older children tested, three $(0.7 \%$, 95\% CI $0.2-2.3 \%)$ were HBsAg positive. None of the 171 young children tested were $\mathrm{HBsAg}$ positive. Overall, of the 18 persons who were HBsAg positive, only one was aware of their infection. HBsAg prevalence was $1.8 \%$ in rural areas (95\% CI: $0.8-4.1 \%$ ) and $0.7 \%$ in urban areas (95\% CI: 0.2-2.3\%). All 18 HBsAg-positive persons were born in Bhutan.

\section{Factors associated with chronic HBV infection}

The prevalence of HBsAg did not vary according to the exposures examined, including traditional or formal health care occupation, history of blood transfusion, or invasive treatment by traditional healers (Table 2).
Among young children, vaccination coverage was higher for the third dose (92\%) of the routine series than for the birth dose (70\%) (Table 3). Among older children, who were born before the introduction of the HepB-BD, coverage was much lower both for the HepBBD (16\%) and for the third dose (59\%), than among young children (Table 3). The low prevalence of HBsAg, small sample size, and moderate-to-high vaccination coverage prevented comparisons between vaccination status and HBsAg status, as confidence intervals were too wide (Table 3).

\section{HCV infection prevalence}

Of the 1150 older children and adults tested, four were positive for anti-HCV $(0.3 \%, 95 \%$ CI: $0.1-0.8 \%$, Table 1$)$. Prevalence did not significantly vary with age; $0.5 \%$ (one of 375, 95\%CI: 0.1-3.4\%) among older children and $0.2 \%$ (three of 775, 95\%CI: 0.1-0.7\%) among adults. All four persons who were anti-HCV positive lived in rural areas (0.4\%, 95\% CI: $0.1-1.1 \%)$ and were born in Bhutan; none were aware of their anti-HCV positive status.

\section{Factors associated with HCV infection}

Anti-HCV prevalence did not vary according to traditional or formal health care occupation or history of blood transfusion (Table 2). Anti-HCV prevalence was higher among those with a history of invasive treatment by traditional healers $(0.9 \%)$ than among persons without such a history $(0.1 \%)$, but the $95 \%$ confidence interval of the prevalence ratio included one (Table 2).

\section{Referral to care}

\section{Referral to care among HBsAg positive persons}

Of the 18 persons who were identified to be HBsAg positive, $12(67 \%)$ could be referred to care (others were

Table 1 Prevalence of chronic HBV infection (HBsAg positive) and serological evidence of past or present HCV infection (anti-HCV positive) by gender, age, residence and country of birth, Bhutan, 2017

\begin{tabular}{|c|c|c|c|c|c|c|c|}
\hline & & \multicolumn{3}{|l|}{$\mathrm{HBsAg}$} & \multicolumn{3}{|c|}{ Anti-HCV } \\
\hline & & Tested & Positive & $\%[95 \% \mathrm{Cl}]$ & Tested & Positive & $\%[95 \% \mathrm{Cl}]$ \\
\hline \multirow[t]{2}{*}{ Gender } & Female & 693 & 7 & $1.3[0.5-3.5]$ & 603 & 3 & $0.3[0.1-1.0]$ \\
\hline & Male & 627 & 11 & $1.9[0.9-3.7]$ & 547 & 1 & $0.2[0.0-1.9]$ \\
\hline \multirow[t]{4}{*}{ Age } & $1-4$ years & 171 & 0 & $0[0-2.1]^{\mathrm{a}}$ & 0 & - & - \\
\hline & $5-17$ years & 375 & 3 & $0.7[0.2-2.3]$ & 375 & 1 & $0.5[0.1-3.4]$ \\
\hline & $1-17$ years & 546 & 3 & $0.5[0.1-1.8]$ & 0 & - & - \\
\hline & $\geq 20$ years & 775 & 15 & $2.0[1.0-4.0]$ & 775 & 3 & $0.2[0.1-0.7]$ \\
\hline \multirow[t]{2}{*}{ Residence } & Rural & 1071 & 16 & $1.8[0.8-4.1]$ & 928 & 4 & $0.4[0.1-1.1]$ \\
\hline & Town & 250 & 2 & $0.7[0.2-2.3]$ & 222 & 0 & - \\
\hline \multirow[t]{2}{*}{ Country of birth } & Bhutan & 1312 & 18 & $1.6[0.8-3.2]$ & 1141 & 4 & $0.3[0.1-0.8]$ \\
\hline & India & 7 & 0 & - & 7 & 0 & - \\
\hline Total & & 1321 & 18 & $1.6[0.8-3.2]$ & 1150 & 4 & $0.3[0.1-0.8]$ \\
\hline
\end{tabular}

${ }^{\mathrm{a}}$ Exact confidence interval 
Table 2 Prevalence of chronic HBV infection (HBsAg positive) and serological evidence of past or present HCV infection (anti-HCV positive) according to selected characteristics, Bhutan, 2017

\begin{tabular}{|c|c|c|c|c|c|c|c|c|}
\hline \multirow[t]{2}{*}{ Outcome } & \multirow[t]{2}{*}{$\begin{array}{l}\text { Past exposure to formal } \\
\text { or traditional health care }\end{array}$} & \multicolumn{3}{|c|}{$\begin{array}{l}\text { Prevalence among persons } \\
\text { with the characteristic }\end{array}$} & \multicolumn{3}{|c|}{$\begin{array}{l}\text { Prevalence among persons } \\
\text { without the characteristic }\end{array}$} & \multirow[t]{2}{*}{$\begin{array}{l}\text { Prevalence } \\
\text { Ratio [95\% Cl] }\end{array}$} \\
\hline & & $\mathrm{N}$ & Positive & $\%[95 \% \mathrm{Cl}]$ & N & Positive & $\%[95 \% \mathrm{Cl}]$ & \\
\hline \multirow[t]{5}{*}{ Chronic HBV infection (HBsAg-positive) } & Village health worker & 13 & 0 & - & 762 & 15 & $2.0[1.0-4.1]$ & - \\
\hline & Health care worker & 13 & 0 & - & 762 & 15 & $2.0[1.0-4.1]$ & - \\
\hline & Traditional healer & 5 & 0 & - & 764 & 15 & $2.0[1.0-4.1]$ & - \\
\hline & Blood transfusion & 59 & 1 & $1.7[0.2-12.3]$ & 713 & 14 & $2.0[1.0-4.3]$ & $0.8[0.1-7.8]$ \\
\hline & $\begin{array}{l}\text { Invasive treatment } \\
\text { by healer }\end{array}$ & 156 & 6 & $3.7[1.6-8.3]$ & 550 & 7 & $1.4[0.5-3.7]$ & $2.6[0.7-9.6]$ \\
\hline \multirow{5}{*}{$\begin{array}{l}\text { Serological evidence of past or present } \\
\text { HCV infection (anti-HCV) }\end{array}$} & Village health worker & 13 & 0 & - & 762 & 3 & $0.2[0.1-0.7]$ & - \\
\hline & Health care worker & 13 & 0 & - & 762 & 3 & $0.2[0.1-0.7]$ & - \\
\hline & Traditional healer & 5 & 0 & - & 764 & 3 & $0.2[0.1-0.7]$ & - \\
\hline & Blood transfusion & 59 & 0 & - & 713 & 3 & $0.2[0.1-0.8]$ & - \\
\hline & $\begin{array}{l}\text { Invasive treatment } \\
\text { by healer }\end{array}$ & 156 & 2 & $0.9[0.2-3.7]$ & 550 & 1 & $0.1[0.0-0.6]$ & $12.6[1.0-160.0]$ \\
\hline
\end{tabular}

lost to follow up). Of those, three (25\%) were HBV DNA positive. One HBV DNA positive person had an increased alanine amino transferase level, and was eligible for treatment according to 2015 WHO HBV treatment guidelines; this individual began Tenofovir treatment.

\section{Referral to care among anti-HCV positive persons}

Of the four persons who were identified to be anti-HCV positive, none were HCV RNA positive. None of the anti-HCV positive persons was eligible for treatment according to the 2018 WHO HCV treatment guidelines.

\section{Discussion}

One of the purposes of this biomarker survey was to evaluate the impact of hepatitis $B$ vaccination among children. In 2016, the Immunization Technical Advisory Group of the WHO South East Asia Region set a goal to reduce the HBsAg prevalence among 5 year old children to $<1 \%$ by
2020, in agreement with the goal of the GHSS on Viral Hepatitis [2]. In this study, children aged 5-17 years had a $\mathrm{HBsAg}$ prevalence of $0.7 \%$, suggesting that the regional goal might have been already achieved, but the wide confidence limits (range: $0.2-2.3 \%$ ) prevent a definitive conclusion. In this survey, $92 \%$ of $1-4$ year old children had received three hepatitis B vaccine doses, and $70 \%$ had received three doses and a birth dose; however, only $59 \%$ of the $5-17$ years of age had received three hepatitis $B$ vaccine doses. These findings are consistent with hepatitis $B$ vaccination coverage from administrative reports. Pre-vaccine HBsAg seroprevalence was estimated to be $5.2 \%$ among children $0-12$ years of age [5], which represents an $86 \%$ reduction in the prevalence of chronic HBV infection. This reduced prevalence in children is expected to reduce morbidity and mortality from HBVrelated chronic liver diseases in the coming years [7]. In addition, when girls who were vaccinated as infants reach childbearing age, Bhutan will benefit from a second-

Table 3 Vaccination coverage and prevalence of chronic HBV infection (HBsAg positive) according to vaccination status, Bhutan, 2017

\begin{tabular}{|c|c|c|c|c|c|c|c|c|}
\hline & & \multirow{2}{*}{\multicolumn{3}{|c|}{$\begin{array}{l}\text { Weighted average of } \\
\text { vaccination coverage }\end{array}$}} & \multicolumn{4}{|c|}{$\begin{array}{l}\text { Prevalence of HBsAg among } 171 \text { children 1-4 years and } 375 \\
\text { children 5-17 years with test performed and available }\end{array}$} \\
\hline & & & & & \multicolumn{2}{|c|}{ Among vaccinated } & \multicolumn{2}{|c|}{ Among unvaccinated } \\
\hline & & Vaccinated & Total & $(\%)$ & N/Total (\%) & $\begin{array}{l}95 \% \text { confidence } \\
\text { interval }\end{array}$ & N/Total (\%) & $\begin{array}{l}95 \% \text { confidence } \\
\text { interval }\end{array}$ \\
\hline \multirow[t]{3}{*}{${\text { Children } 1-4 \text { years }^{a}}$} & Birth dose $^{b}$ & 136 & 185 & $70 \%$ & $0 / 127(0 \%)$ & - & $0 / 44(0 \%)$ & - \\
\hline & Third dose & 174 & 185 & $92 \%$ & 0/164 (0\%) & - & $0 / 7(0 \%)$ & - \\
\hline & Three doses, with birth dose & 135 & 185 & $70 \%$ & $0 / 126(0 \%)$ & - & $0 / 45(0 \%$ & - \\
\hline \multirow[t]{2}{*}{ Children $5-17$ years $^{c}$} & Birth dose $^{d}$ & 45 & 394 & $16 \%$ & $1 / 40(2.4 \%)$ & $0.4-15.0$ & $2 / 335(0.4 \%)$ & $0.1-1.5$ \\
\hline & Third dose & 253 & 394 & $59 \%$ & $3 / 246(1.1 \%)$ & $0.3-3.9$ & 0/129 (0\%) & - \\
\hline
\end{tabular}

\footnotetext{
a171 specimens tested

${ }^{\mathrm{b}}$ Any birth dose, $128 / 136$ given within $24 \mathrm{~h}$ of birth

c375 specimens tested
}

${ }^{d}$ Any birth dose, 38/45 given within $24 \mathrm{~h}$ of birth 
generation effect of decreased mother-to-child transmission that will further reduce the incidence of chronic HBV infections in children 5 years of age [9]. Chronic HBV infections in children 5 years of age is the indicator of the 'combatting hepatitis' target of the sustainable development goal [10]. In 2019, the South-East Asia Region Expert Panel for Verification of hepatitis B control [11] considered the length of the nationwide vaccination programme, schedule, coverage and HBsAg prevalence in this survey and concluded that the country had achieved the hepatitis B control target of HBsAg $1 \%$ in children at least 5 years old. The Regional Expert Panel underlined that while a point prevalence of $<1 \%$ was obtained, the 95\% confidence interval was larger than desired, thus alone not allowing a definite conclusion. However, evidence from the vaccination programme, including long history of hepatitis B vaccination, the high, sustained coverage in the last decade and the inclusion of a birth dose in 2011 added confidence to the finding of $<1 \%$ HBsAg prevalence in children 5-17 years old.

This biomarker survey was also an opportunity to evaluate the HBsAg prevalence among adults in the context of developing a strategy to identify and manage persons with chronic HBV infection. Overall, among persons 20 years of age or older, HBsAg the prevalence was $2 \%$, lower than in the 1995 survey $(6.3 \%$ among persons 24 years of age or older) [5]. Projections of this prevalence to the adult population in Bhutan (about 500, 000 persons) suggest an estimated 5000 to 20,000 persons living with chronic HBV infection in the country in 2017. Vaccination cannot explain the reduction of HBsAg in adults during 1995-2017, since this age cohort was born before hepatitis B vaccine was introduced in the routine childhood immunization schedule. One possible explanation for the reduction in HBsAg prevalence would be that endemicity started to decrease because of improved infection control practices before immunization [12]. Another possible explanation is that older age groups might have suffered increased mortality from HBV infection [13], and the increased mortality would have reduced the prevalence between 1995 and 2017. With the relatively low prevalence among adults, a focused testing and treatment strategy might be considered in Bhutan (e.g., testing pregnant women, individuals with chronic liver diseases, populations with history of high-risk exposures, and blood donors) [6]. WHO recommends routine testing for all adults only if the HBsAg prevalence exceeds $2-5 \%$ in the general population [6].

Overall, the prevalence of anti-HCV was lower $(0.3 \%)$ than in the 1995 biomarker survey (1.3\%). Projections of the $\mathrm{HCV}$ infection prevalence to the adult population in Bhutan, and assuming $80 \%$ of anti-HCV positive persons are HCV RNA positive (the proportion estimated for India [14]) suggest an estimated 400 to 2800 persons living with chronic HCV infection in the country in 2017.
Two factors could explain the lower prevalence in 2017 than in 1995. First, the serological assay that we used in 2017 may have had a higher sensitivity and specificity than the Abbott ELISA assay used in 1995, an earlier generation test that was less sensitive and less specific than the current ones [15-17]. Seroprevalence studies done before 2000 with first and second generation anti$\mathrm{HCV}$ tests had too many false positive [14]. Second, under the assumption that transmission took place on a larger scale in the past, some older individuals with $\mathrm{HCV}$ infection may have died from chronic liver disease in the meantime, which would have led to a reduction of prevalence. In many countries, $\mathrm{HCV}$ transmission was more intense at the end of the twentieth century than it has been in the twenty-first century $[14,18]$.

Our survey also provided an opportunity to examine prevalence of $\mathrm{HCV}$ infection according to histories of possible exposures. Cross sectional surveys that examine serological evidence of past or present $\mathrm{HCV}$ infection are not a good way to explore the modes of transmission of viruses like HCV that lead to chronic infection. However, results of our analysis suggest that the prevalence of anti-HCV was higher among persons who had received invasive procedures from traditional healers. This finding is consistent with what is known of the modes of transmission of HCV [19]. Given the low prevalence of chronic HCV infection in Bhutan, a focused testing and treatment strategy might be considered for individuals with chronic liver diseases, populations with history of high-risk exposures, and blood donors [6]. General population testing may not be appropriate as WHO recommends routine testing for $\mathrm{HCV}$ infection for adults only if the $\mathrm{HCV}$ infection prevalence exceeds $2-5 \%$ in the general population [6].

Our survey had a number of limitations. First, some questions relied on recall data, such as history of exposure to invasive procedures, some of which might have occurred long ago, and vaccination status of some children. Secondly, while participation was high, some selected households did not participate, and it is unknown if these households were different from participating households. The subsets of individuals with exposures of interest were quite small; therefore, we might have failed to find significant associations with infection, even if they existed. Overall, our small sample size and low prevalence did not allow us to identify population subgroups that should be tested for HBV or HCV infection. Thirdly, expected differences in HBsAg prevalence estimates between age categories may have been diluted, as older children also had received birth dose while some adults could have been vaccinated as young adults. Fourth, the low proportion of HBsAg and anti-HCV positive persons who were positive for HBV DNA (3/1) and HCV RNA (0/4) may point to a need to confirm 
positive serological tests with a second test. Finally, we did not examine children born when hepatitis $B$ vaccine was first introduced in the routine childhood vaccination schedule (i.e., from 1997 to 1999), preventing us from inferring the prevalence estimate found in this study directly to the entire population of Bhutan.

\section{Conclusions}

In conclusion, our survey documented that the prevalence of HBV infection is likely to be lower than $1 \%$ in the children 5-17 years of age, probably because of moderate-to-high vaccination coverage. We also found that the prevalence of HBV infection in the total population was under the threshold of $2 \%$ (low endemicity) while the past or present $\mathrm{HCV}$ infection prevalence was very low $(0.3 \%)$. Based on these results, efforts should continue to reach high coverage of the timely birth dose along with completion of the hepatitis $B$ vaccine series [20]. For adults, HBV and HCV testing might reasonably be restricted to pregnant women, blood donors, individuals with chronic liver diseases, and other groups with history of high-risk exposures such as injection drug use for HCV infection.

\section{Abbreviations}

Anti-HCV: Hepatitis C virus antibody; Cl: Confidence Intervals; HBV: Hepatitis B virus; HCV: Hepatitis C virus; HBsAg: Hepatitis B surface antigen; HepBBD: Hepatitis B birth dose; IgG: Immunoglobulin G; RCDC: Royal Centre for Disease Control

\section{Acknowledgements}

We are grateful to Mick Mulders, Anita Sands, Lara Vojnov and Philippa Easterbrook (WHO) and to Rania Tohme and Jim Alexander (United States Centers for Disease Control and Prevention) for comments and suggestions on the protocol and the manuscript.

\section{Authors' contributions}

NT, GPD, UW, SW, LK, SP, BBR and SW collaborated to prepare the protocol of the study on the basis of a WHO template (https://apps.who.int/iris/ bitstream/handle/10665/280099/WHO-CDS-HIV-19.3-eng.pdf?ua=1). YJFH drafted the WHO template protocol and the manuscript. FN, MP, and KW edited the protocol and contributed to the data analysis. SP and SW led the analysis of the laboratory specimens. All authors reviewed and edited the manuscript.

\section{Funding}

This project was supported financially by the United States Centers for Disease Control and Prevention (US CDC). US CDC employees contributed to this work and so-signed the paper.

\section{Availability of data and materials}

The datasets used and/or analysed during the current study are available from the corresponding author on reasonable request.

\section{Ethics approval and consent to participate}

The Research \& Ethical Board of Health, Bhutan, and the WHO Research Ethics Review Committee approved the survey protocol after the necessary amendments (Bhutan: REBH/Approval/2017/008; WHO: ERC.0002874). This activity was reviewed in accordance with CDC human research protections procedures and was determined to be nonresearch, programme evaluation. Participants provided written consent for themselves. For children and adolescents $0-18$ years of age, parents or guardians provided written consent. Adolescents 12-18 years of age provided written assent in addition to consent from parents / guardians.
Consent for publication

Not applicable.

\section{Competing interests}

None of the authors have competing interests.

\section{Author details}

'Department of Public Health, Ministry of Health, Thimphu, Bhutan

${ }^{2}$ Department of Medicine, Jigme Dorji Wangchuk National Referral Hospital, Thimphu, Bhutan. ${ }^{3}$ WHO Country Office, Thimphu, Bhutan. ${ }^{4}$ Royal Centre for Disease Control, Department of Public Health, Ministry of Health, Thimphu, Bhutan. ${ }^{5}$ WHO Headquarters, 20 Avenue Appia, 1211 Geneva, Switzerland. ${ }^{6}$ WHO Regional Office for the Eastern Mediterranean Region, Monazamet El Seha El Alamia Street, Nasr City, Po Box 7608, Cairo 11371, Egypt. ${ }^{7}$ United States Centers for Disease Control and Prevention, Atlanta, GA, USA. ${ }^{8}$ WHO Regional Office for the South East Asia Region, New Delhi, India.

Received: 18 March 2019 Accepted: 17 June 2020

Published online: 08 July 2020

\section{References}

1. WHO. Global hepatitis report, 2017. Available at http://www.who.int/ hepatitis/publications/global-hepatitis-report2017/en/ (Accessed 19 June 2017)..

2. WHO. Draft global health sector strategies Viral hepatitis, 2016-2021. Report by the Secretariat. Agenda item A69/32. Available http://apps.who.int/gb/ ebwha/pdf_files/WHA69/A69_32-en.pdf?ua=1 (Accessed 21 June 2016).

3. WHO. Technical considerations and case definitions to improve surveillance for viral hepatitis Surveillance document. Tech Rep. 2016; ISBN ISBN 97892 4154954 . Available at http://apps.who.int/iris/bitstream/10665/204501/1/ 9789241549547_eng.pdf?ua=1 (Accessed 21 June 2016).

4. WHO. Monitoring and evaluation for viral hepatitis B and C: Recommended indicators and framework. Tech Rep. 2016; ISBN 9789241510288. Available at http://apps.who.int/iris/bitstream/10665/204790/1/97892415102 88_eng.pdf (Accessed 21 June 2016).

5. Da Villa G, Andjaparidze A, Cauletti M, Franco E, Roggendorf M, Sepe A, Zaratti L. Viral hepatitis in the Bhutanese population: preliminary results of a seroepidemiological investigation. Res Virol. 1997;148:115-7.

6. Guidelines on hepatitis B and C testing. Geneva: World Health Organization; 2017 (http://www.who.int/hepatitis/publications/guidelines-hepatitis-c-btesting/en/, Accessed 19 Mar 2017).

7. World Health Organization. Hepatitis B vaccines: WHO position paper - July 2017. Wkly Epidemiol Rec. 2017;92(27):369-92 PMID: 28685564.

8. Guidance for organizing external quality assessment schemes for HIV serological testing. Geneva: UNAIDS; 1996 [UNAIDS/96.5] (http://www.who. int/diagnostics_laboratory/quality/en/EQAS96.pdf, Accessed 4 Dec 2015).

9. Hutin Y, Desai S, Bulterys M. Preventing hepatitis B virus infection: milestones and targets. Bull World Health Organ. 2018;96:443-443A.

10. World health statistics 2016. Monitoring health for the SDGs, sustainable development goals. Geneva: World Health Organization; 2016. (http://apps. who.int/iris/bitstream/10665/206498/1/9789241565264_eng.pdf?ua=1, Accessed 10 Mar 2017).

11. WHO, 2019. Guidelines for verification of achievement of hepatitis B control target through immunization in the WHO South-East Asia Region. Available at: http://www.searo.who.int/entity/immunization/highlights/verificationguidelines.pdf (Accessed: 5 Dec 2019).

12. Pépin J, Abou Chakra CN, Pépin E, Nault V, Valiquette L. Evolution of the global burden of viral infections from unsafe medical injections, 2000-2010. PLoS One. 2014;9(6):e99677. https://doi.org/10.1371/journal.pone.0099677.

13. Bixler D, Zhong Y, Ly KN, Moorman AC, Spradling PR, Teshale EH, Rupp LLB, Gordon SC, Boscarino JA, Schmidt MA, Daida YG, Holmberg SD, CHeCS Investigators. Mortality among Patients with Chronic Hepatitis B (CHB) Infection: the Chronic Hepatitis Cohort Study (CHeCS). Clin Infect Dis. 2018. https://doi.org/10.1093/cid/ciy598 [Epub ahead of print].

14. Blach S, Zeuzem S, Manns M. Global prevalence and genotype distribution of hepatitis C virus infection in 2015: a modelling study. Lancet Gastroenterol Hepatol. 2016;2:161-76.

15. Kamili S, Drobeniuc J, Araujo AC, Hayden TM. Laboratory diagnostics for Hepatitis C virus infection. Clin Infect Dis. 2012;55(suppl_1):S43-8. https:// doi.org/10.1093/cid/cis368. 
16. Mazzotta L, Landucci G, Pfanner L, Carlini A, Angelini D, Giusti R, Antonelli A. Comparison between first and second generation tests to determine the frequency of anti-HCV antibodies in uremic patients in replacement dialytic therapy. Nephron. 1992;61:354-5.

17. Gupta E, Bajpai M, Choudhary A. Hepatitis C virus: screening, diagnosis, and interpretation of laboratory assays. Asian J Transfus Sci. 2014;8:19-25.

18. Saraswat V, Norris S, de Knegt RJ, Sanchez Avila JF, Sonderup M, Zuckerman E, et al. Historical epidemiology of hepatitis $\mathrm{C}$ virus (HCV) in select countries. J Viral Hepat. 2015;2(Suppl 1):6-25.

19. Thursz M, Fontanet A. HCV transmission in industrialized countries and resource-constrained areas. Nat Rev Gastroenterol Hepatol. 2014;1:28-35. https://doi.org/10.1038/nrgastro.2013.179 Epub 2013 Oct 1.

20. Regional framework for the triple elimination of mother-to-child transmission of HIV, hepatitis B and syphilis in Asia and the Pacific 20182030. WPR/RC68/7. Geneva: World Health Organization; 2018. Available from: http://www.wpro.who.int/about/regional_committee/68/documents/ wpr_rc68_7_annex_hiv_hepa_syphilis.pdf?ua=1\&ua=1 [cited: 2018 May 23].

\section{Publisher's Note}

Springer Nature remains neutral with regard to jurisdictional claims in published maps and institutional affiliations.

Ready to submit your research? Choose BMC and benefit from:

- fast, convenient online submission

- thorough peer review by experienced researchers in your field

- rapid publication on acceptance

- support for research data, including large and complex data types

- gold Open Access which fosters wider collaboration and increased citations

- maximum visibility for your research: over $100 \mathrm{M}$ website views per year

At $\mathrm{BMC}$, research is always in progress.

Learn more biomedcentral.com/submissions 